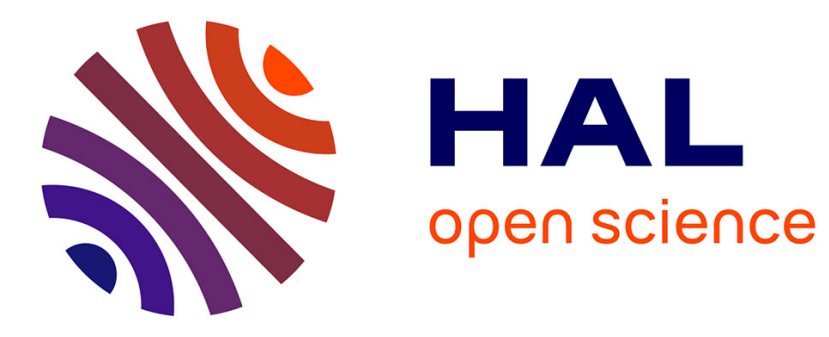

\title{
Stereoscopic Images from Computed Tomography Angiograms
}

François Lechanoine, Mykyta Smirnov, Giulia Armani-Franceschi, Pedro Carneiro, Philippe Cottier, Christophe Destrieux, Igor Lima Maldonado

\section{- To cite this version:}

François Lechanoine, Mykyta Smirnov, Giulia Armani-Franceschi, Pedro Carneiro, Philippe Cottier, et al.. Stereoscopic Images from Computed Tomography Angiograms. World Neurosurgery, 2019, 128, pp.259-267. 10.1016/j.wneu.2019.04.257 . hal-02548442

\section{HAL Id: hal-02548442 \\ https://hal.science/hal-02548442}

Submitted on 20 Apr 2020

HAL is a multi-disciplinary open access archive for the deposit and dissemination of scientific research documents, whether they are published or not. The documents may come from teaching and research institutions in France or abroad, or from public or private research centers.
L'archive ouverte pluridisciplinaire HAL, est destinée au dépôt et à la diffusion de documents scientifiques de niveau recherche, publiés ou non, émanant des établissements d'enseignement et de recherche français ou étrangers, des laboratoires publics ou privés. 


\title{
Stereoscopic images from computed tomography angiograms
}

\author{
Journal choice: WORLD NEUROSURGERY
}

OBJECTIVE: To present an adaptation of the anaglyph photography technique to be used with radiological images from computed tomography angiograms, enabling stereoscopic visualization of the patient's individual abnormal vascular anatomy for teaching, case discussion, or surgical planning purposes. METHODS: Traditional anaglyph procedures with actual objects yield two independent photographs, simulating the image perceived by each eye. Production of anaglyphs from angiograms involve three basic procedures: volume rendering, image capture, and image fusion. Volume renderings were reconstructed using a free, open-source DICOM (Digital Imaging and Communications in Medicine) reader. Subsequently, the virtual object was positioned to mimic the operator's angle of view, and different perspectives of the reconstructed volume could be obtained through exclusively horizontal rotation. The two images were then fused after their color composition has been modified so that each eye would perceive only one image when using anaglyph glasses. RESULTS: Forty-three angiograms were reviewed for the purpose of this study and a total of six examinations were selected for illustration of the technique. Stereoscopic display was possible for all of them and in the three types of support tested: computer monitor, tablet, and smartphone screens. CONCLUSION: Anaglyph display of computed tomography angiograms is an effective and low-cost alternative for the stereoscopic visualization of a patient's individual intracranial vascular anatomy.

Keywords: tomography; three-dimensional image; computer-assisted three-dimensional imaging; cerebrovascular disorders; neuroanatomy; computed tomography angiography; stereoscopic vision; middle cerebral artery, internal carotid artery; circle of Willis 


\section{INTRODUCTION}

The mastery of three-dimensional (3D) vascular anatomy by the neurosurgical apprentice is particularly complex. In this context, surgical simulators, augmented or virtual reality devices, are being progressively used as educational tools for the goal of displaying the intracranial anatomy as closely as possible to the operative reality. Most of these techniques, however, require high-cost technical platforms and qualified human assistance.

In the last two decades, stereoscopic photography has proven to be of great value for teaching neurosurgical anatomy (1-11). It does not replace simulators, but when used for documenting cadaver dissections, it appears to facilitate understanding of how anatomical structures are distributed in space. For printing, an inexpensive anaglyph approach originally described in the nineteenth century, can be used $(12,13)$. In that method, a stereoscopic color picture is generated by superimposing the left and right angles of view of a stereo pair. The original colors are then modified so that each eye perceives only one image when the corresponding filtering glasses are used.

Here, we present an adaptation of the anaglyph photography technique that can be used with radiological images of computed tomography (CT) angiograms, enabling stereoscopic visualization of a patient's individual abnormal vascular anatomy, for the purpose of teaching, case discussion, or surgical planning. Through a simple algorithm, it allows the operator to perform stereoscopic reconstructions, select the desired parallax, and simulate the desired surgical perspectives. 


\section{METHODS}

\section{Image Acquisition}

Images were acquired on a 64-detector row spiral CT (CT Discovery, GE Heathcare, Milwaukee, Wisconsin). Fast, thin-section volumetric spiral (helical) were performed before and after intravenous injection of contrast medium using the following parameters: $120 \mathrm{kV}, 170 \mathrm{~mA}, 0.4 \mathrm{~s}$ revolution time. Image reconstructions were as follows: $0.625-\mathrm{mm}$ slice thickness, $0.6 \mathrm{~mm}$ spacing, $512 \times 512$ matrix, and $228-\mathrm{mm}$ field of view. Scan coverage spanned the first cervical vertebra to the vertex. Arterial enhancement was obtained by the intravenous injection of $50 \mathrm{ml}$ of nonionic contrast media into an antecubital vein at $4 \mathrm{~mL} / \mathrm{s}$ (Ultravist 370 , Bayer Healthcare, Mississauga, Canada). Imaging was autotriggered by the appearance of contrast media in the internal carotid at C2 level.

The images of 43 examinations were reviewed for demonstration of the technique: 12 men and 31 women, with a mean age of $53.5 \pm 15.6$ years (mean $\pm S D$, range $15-87$ ).

\section{Preparation of anaglyphs}

The general method for preparing anaglyph images classically consists of three essential steps: object preparation, stereoscopic photography, and image fusion. In this specific case, the object was virtual, i.e., a tomographic examination. Thus, the first post-processing step was 3D reconstruction by volume rendering. Three basic procedures resulted from adaptations of the technique and are described below.

\section{1) Volume rendering}

Currently, either freeware or paid software enable semi-automated stereoscopic image generation even from a single picture. This option is available in the OsiriX and Horos applications for reconstructions using a different method: surface rendering. Nevertheless, in surface rendering, the reconstructed volume is monochromatic, and important details of small structures are lost, particularly small depressions and the spaces between the bony structures and the vessels, which are better perceived if a wider range of colors is used. In addition, parallax customization is not possible with automated anaglyph generation after surface rendering. As neurosurgery deals with small structures, and different degrees of depth perception may be needed for adequate 
simulation, we opted to use volume rendering and to build the stereoscopic images in a customized stepwise method in a photography post-processing application, which will be described in the next section.

Volume rendering reconstructions were performed using the free, open-source software Horos (version 3.3.5, Nible Co., Annapolis, USA). All slices were checked visually for quality, presence of movement, and metallic or other types of artifacts that could compromise the procedure. The 3D volume rendering tool was used with the following parameters for optimization: contrast medium, level of detail fine, resolution best, shading On (default presets), and filter none (Fig. 1A). Two different view modes are possible: parallel and perspective, in which the forms are modified for augmented perspective perception.

After reconstructing the 3D volume, additional manual window adjustments allowed the desired levels of visual optimization according to the final objective of presentation: skin, bones, or vessels. As we aimed to demonstrate vascular structures, the definition of the final window setting was obtained after skull opening and direct visualization of the reconstructed vascular tree.

The next step was the removal of parasitic elements. The Scissor Editing tool was used to remove an eventual foreign object such as head support, blanket, or tracheal tube. To do so, the reconstructed 3D object was rotated at various angles of projection and these elements were removed until the surrounding space was clear. For the exposition of deep structures, the same tool could remove superficial anatomical elements (Fig. 1B). To simulate the skull base and for vascular visualization in the operative context, a virtual craniotomy was performed according to the method described by Spiriev et al. in 2017 (14).

\section{2) Image Capture}

The essential element of this step is displaying the prepared image in the final perspective. When the purpose is to simulate a surgical situation, the object position should imitate the operator's angle of view. For a pterional craniotomy, for example, different degrees of rotation and extension of the head are possible depending on the vascular structure that is to be visualized (15). After defining them, the following algorithm was used to decompose movements, reproducible steps, and to increase positioning precision: 1 ) In top view ( $S$ position of Horos software), the head was rotated according to the surgical position as if the operator's eyes were aligned with the operating table (z-axis, Fig. 1C); 2) the head was extended or flexed according to the planned approach (Fig. 1D). The exact angles of rotation and extension were displayed on the Horos workspace 
and could be checked if necessary; 3) after a virtual craniotomy, the object was rotated again to simulate the surgeon's perspective according to their desired eye position (Fig. 1E).

Care was taken to avoid positioning target anatomical structures at the edges of the reconstructed image. This was because, in the next steps of colorimetric transformation for stereoscopic visualization, a vertical band of artifacts is generated on the right and left picture edges, and must be removed. As the final result depends on the superposition of images with different colors, these bands occur wherever only one image is displayed, and their hues are similar to that of the cyan/red glass filters. In traditional photography, these zones tend to be larger with increasing parallax for two pictures of the same size. With virtual objects, it should be kept in mind that the crucial anatomical elements to be demonstrated must remain distant from the periphery of the volumerendered angiogram during image capture. The image of the virtual object is then exported as an image file. This may be performed using either Horos or dedicated capture applications. We used the .jpeg file format.

Traditional anaglyph procedures with actual objects yield two independent photographs. They simulate the image perceived by each eye. These images are slightly different, although very similar. They offer different perspectives, and when displayed in a row, they give the small impression of object movement or rotation. When fused and viewed with special glasses, each eye perceives only one of the images. The cerebral interpretation of the simultaneous perception of the two different images recreates the sensation of a stereoscopic view. It is possible to obtain images of an actual object by moving a camera horizontally on a rectilinear track or a curved track (with a concavity facing the object), or by using two cameras. There are several protocols for determining the ideal distance between the two photographs. A common one involves moving the camera $1 / 30$ of the distance from the object.

A virtual image involves no cameras or displacements, but different perspectives of the reconstructed volume can be obtained through exclusive horizontal rotation. It must be in the horizontal plane to simulate the natural right and left eye perceptions, a situation in which all elements of the images are aligned on the $x$-axis. For the $1 / 30$ rule, the necessary rotation was calculated to be roughly 2 degrees (Fig. $2 A$ ). For additional perspective effect, such as that experienced when the object is closer, supplementary rotation may still be calculated (Fig. 2B), but under the condition of further inspection after merging, as it may produce exaggerated dissimilarity between the two images and unpleasant artifacts due to binocular rivalry (16). 
An initial image of the object was exported after ensuring that all essential anatomical structures were displayed and that they did not extend to the left or right edges. Next, strictly horizontal rotation ( $y$-axis) was performed and the image was exported again. The image richer in background elements on the left side of the screen was entitled Left, as it was the virtual representation of what would be obtained with the left picture in classical photography. In this image, the details of deep structures were partially hidden by that of the more superficial planes on the right side of the displayed image, but not on the left. Conversely, the image in which the deep elements were more apparent on the right was entitled Right.

\section{3) Image Fusion}

We used Adobe PhotoShop CS5 Extended version 12.0 (Adobe Systems Inc., San José, USA) for merging images. We chose not to use automated anaglyph generators and to systematically perform manual layer superpositioning to enable real-time checking of the final result and the identification of errors that might require the repetition of previous steps (such as rotation on the $y$ - or $z$-axis).

The images were first checked for quality. They were then imported into the same file in the form of superposed layers and named Right and Left using the same criteria described above. We systematically positioned the Right image as the front layer. We checked the rotation effect visually via intermittent occultation of the image. Then, we reduced the density of the front Right layer to $50-75 \%$, so that the details of the back Left layer were also visible by transparency. The Right layer was then moved horizontally until superpositioning of the desired anatomical elements was achieved. The point of maximum coincidence was selected taking into consideration the fact that it is also the point of maximum sharpness in the generated anaglyph, and perceived at screen level. All other points, i.e., more superficial or deeper ones, were perceived behind or ahead of it.

Once the relative position of the two images had been determined, the display density of the front image was returned to $100 \%$. The next step consisted of modifying the color composition of the layers so that each eye would perceive only one layer while using anaglyph glasses. For this, the red channel of the RBG (red blue green) system of the Right front layer was turned off, so that it was displayed in blue-green tones; the $G$ and B channels of the Left back layer were turned off and it was displayed in red tones. Subsequently, the display mode of the Right layer was switched to Screen. From that moment, the stereoscopic effect could be perceived with anaglyph red/cyan glasses. For any relative position adjustment, the Right image was further moved during 
continuous assessment of the final result. The final step consisted of image cropping to remove the right- and left-edge artifacts, light enhancement when necessary, and image exporting. The .psd and .jpeg file formats were used for archiving and displaying, respectively. 


\section{RESULTS}

The present algorithm for preparing stereoscopic anaglyph images was applied to 10 CT angiograms. Figures 3 and 4 summarize the graphical results.

Several scenarios were prepared, including an overview of the arterial circle of the brain (Fig. 3). A selection of other illustrations demonstrates the possibility of applying the method with different angles of view and levels of enlargement of the rendered volumes from a microsurgical perspective. Figure $4 \mathrm{~A}$ shows the intracranial internal carotid artery and its bifurcation. Figures $4 \mathrm{~B}, 4 \mathrm{C}$, and $4 \mathrm{D}$ depict pathological cases of aneurysms of the posterior communicating artery, anterior communicating artery, and basilar artery, respectively, with their anatomical relationships with the skull base and other vascular structures. These reconstructions revealed a broad spectrum of options in which the technique can be used to obtain stereoscopic vision from computed tomography angiograms. Adequate depth perception was obtained for all mentioned aneurysmal implantation sites. 


\section{DISCUSSION}

We present a new approach for stereoscopic display of intracranial CT angiograms. It consists of a simple algorithm comprising volume rendering, rotation, and adapted anaglyph technique.

In humans, vision is the main means of environmental perception (17). Monocular vision enables the interpretation of relative object positions by analyzing sizes, colors, shadows, and previous knowledge of their original shapes. It is often sufficient for simple activities, but insufficient for complex ones $(18,19)$. On the other hand, aligned binocular vision enables complete understanding of depth due to the simultaneous perception of objects in the scene from two different angles $(18,20)$. The relationship between the main axes of the two retinas is hence the main enabling factor of accurate spatial orientation.

The first stereoscope was reported in the 1830s by Sir Charles Wheatstone (21). The purpose of the instrument was to provide a 3D perception of 2D images reflected in perpendicular mirrors. This technique was developed parallel to photography, which contributed to the popularization of both in the second half of the nineteenth century (6). At that time, W. Rollmann started the first experiences of anaglyph stereoscopy with drawings (12). Joseph d'Almeida, a French physicist, accurately presented stereoscopic images to a large audience in 1858 (13). To do so, images were projected through red and green filters, while the audience wore tinted eyeglasses of the same color. The approach gave rise to the anaglyph technique (1). In 1896, Elihu Thomson suggested the clinical utility of stereoscopy as applied to radiography, which Sir James Mackenzie Davidson, an English physician, accomplished in 1898, three years after Wilhelm Röentgen's discovery of the $\mathrm{x}$ ray $(7,22)$. In an article published in the British Medical Journal, Sir Davidson described how he used stereoscopy to locate a bullet in the leg of a 14-year-old boy (23). Besides medicine, stereoscopic anaglyph display has been used for teaching and reporting in various scientific fields. Some examples are the depiction of geometric solids in mathematics, dinosaur tracks in paleontology, molecular conformations in chemistry, and elevation maps in geography (24-27).

A basic requisite for neurosurgical planning is the understanding of $3 D$ vascular anatomy. Besides its importance for the operative act per se, many imaging techniques provide bidimensional representations of 3D structures, where mental reconstruction of their spatial distribution requires constant effort. The increasing interest of the neurosurgical community in reducing this effort has been illustrated by the recent increase in publications discussing the interest of interactive volume rendering and 3D printing (28-38). Solid models can be 
used for teaching and treatment planning of complex aneurysms, enabling simulation of clipping, potentially reducing the need for clip replacement and the risk of aneurysm remnants. The use of these models, however, requires expensive equipment and dedicated professionals. Technology development has produced training alternatives, such as interactive stereoscopic virtual reality systems $(10,39)$. Although they facilitate contact of the resident with surgical abnormal anatomy, reduce tensional loads, and allow greater scheduling flexibility (10), they require expensive equipment and a considerable initial investment. The actual benefit of their use is debated.

Classically, the teaching of anatomical forms involves descriptions and 2D image exploration. Plastic models and cadaver dissections are useful strategies, but are subject to limitations in many parts of the world, such as difficulty in obtaining adequately prepared anatomical specimens, religious restrictions, and preservation fluid toxicity (40). Additional obstacles are the impossibility of representing many structures in a single section and the great quantity of details requiring the student's mental reconstruction of objects previously unknown $(41,42)$. In the context of neurosurgical training, even surgical pictures do not allow immediate perception of the 3D disposition of structures $(10,43)$. In this situation, stereoscopy has been suggested as a valuable didactic tool, reducing the distance between the theoretical course and the anatomical reality.

In the educational context, the anaglyph technique has some advantages over other stereoscopic display modes. One main advantage is that it is easy to perform. After a steep learning curve, the user is able to construct images alone without requiring professional assistance. It is accessible to the neurosurgeon who is not trained in advanced radiological techniques. As a further indirect advantage, the user can construct images as needed depending on the case in question, highlighting the structures to be demonstrated and adapting the image processing to the pathology in question.

Dedication applications enable automated conversion of 2D images into anaglyph images. As mentioned earlier, we preferred manual fusion of images when superposing layers because the operator could preview the final result in real-time on the screen during the manipulation. In this manner, the best relative position can be selected and small rotational defects in other axes can be detected (and corrected). Automated applications do not perform such fine manipulations that improve the final results.

Anaglyph is cheap. The low cost makes it widely accessible where virtual reality platforms would be difficult to implement. Volume rendering, basic post-processing, and image capture can be performed with free 
medical image readers or open-source applications. Here, we used the Horos application to load files in DICOM (Digital Imaging and Communications in Medicine) format. The functions used here are present in most basic reader packages. Moreover, red/cyan glasses can be manufactured, easily found worldwide, or ordered online in paper versions for as cheaply as US\$1. This means that the technique may benefit numerous users and that it is suitable for case discussions, educational activities, and electronic diffusion, such as in online journals. Sequential anaglyphs can also be easily combined to create compelling stereo animations (24). Although the impact of the use of stereoscopic display in clinical results is possible, this assessment was beyond of the scope of the present study.

In addition to the low cost, it is worth noting that anaglyph image preparation from CT angiograms requires no additional technical platform beyond the one that often already exists in most services. The image processing technique we describe can be performed in a straightforward manner on personal or portable computers with ordinary configurations. Image manipulation directly on the scanner's acquisition console is also not required.

Generally, the public accepts the use of red/cyan glasses. Often, many users have already experienced or know of this modality of presentation (44). This previous exposure to anaglyph is often advantageous, as it passes to the student an immediate message of simplicity and breaks down barriers to its use. It may also be used for teaching basic neuroanatomy, with the potential for capturing the attention and arousing the interest of young medical students.

The red/cyan anaglyph technique has been used in vascular neurosurgery for photographing cadaver dissections or for intraoperative imaging (1-3,5-11). In a survey involving 15 experienced cerebrovascular surgeons and 15 trainees, 3D documentation of aneurysm clipping was suggested to bring significant improvement to understanding of the anatomical landmarks and the principles of anterior circulation aneurysm surgery (11). The technique presented in our study also allows the study of anatomy specific to actual cases. Although the building of anaglyphs from virtual images is becoming common in other areas of knowledge, this is the first report of its application to CT cerebral angiograms. As images of actual cases are displayed, they can be used as an additional tool for specialized education and discussion of elements that are important for neurosurgical treatment, such as aneurysm shape, orientation, clip choice, and possible approaches. Simple manipulation of volume-rendered angiograms enables the display of vessels from the surgical perspective, enlarged, and within a limited field of view as in the operative situation, which differs greatly from the anatomical position with which most young physicians are familiar. 
The projection of anaglyph stereoscopic images to large audiences is possible but may encounter difficulties. A dark environment, high brightness level, and color matching are necessary. As stereoscopy is produced by color filtering, chromatic aberrations related to the projection system can impair or eliminate the 3D perception. It is generally recognized that the outward effects with this technique are less pronounced than that obtained with polarized light or active glasses. The anaglyph technique has, however, the great practicality of working well with conventional screens and paper supports, most of which the majority of users already have. For polarized light, a considerable initial investment is required to purchase special materials, involving projectors, filters, glasses, and a silver screen. For active techniques, a silver screen is not necessary, but the cost of the remaining dedicated equipment items is higher. Stereoscopy with anaglyph bypasses this initial equipment investment, as it is perceived effectively on conventional computer, tablet, and smartphone screens with acceptable depth effect.

As mentioned earlier, other algorithms have focused on anaglyph display of photography of microsurgical dissections, comparative anatomy, or magnetic resonance examination (24,45-47). Recent works have proposed using the free, open-source application OsiriX as a surgical planning tool $(14,48)$. Spiriev et al. described a step-by-step guide for craniotomy simulation (14). Our algorithm can be easily associated to their technique.

This method has its limitations. Visualizing 3D in anaglyph requires a short adaptation time, which ranges from $<1 s$ to a few seconds and varies with the observer, even in the absence of color perception difficulty. A well-known limitation is related to the display of the red color. The final perception of colors depends on the combination of what is seen through the two eye filters. Difficulty may be encountered in determining the original appearance of red-colored structures. This can be easily resolved by modifying the vascular tree color during volume rendering. Moreover, the perception of different elements by the same eye due to incomplete isolation of the left and right images generates an artifact known as crosstalk $(16,49)$, described as ghosting or a slightly unpleasant blinking sensation with poor focus.

We consider anaglyph of virtual objects obtained from cerebral angiograms a simple and promising technique in neurosurgical education, planning, and reporting. A valuable future research avenue would be the automatization and integration of this display type among the viewing options of post-processing stations and medical image readers. 


\section{CONCLUSION}

We report the first stereoscopic anaglyph reconstructions of CT angiograms. Stereoscopic display of aneurysms and the intracranial vasculature was achieved through volume rendering, rotation, and image fusion. This method may benefit neurosurgeons, teachers, and students by providing an easy, customizable, and lowcost alternative technique for stereoscopic display or printing. 


\section{REFERENCES}

1. Ribas Ricardo Ferreira; Rodrigues, Aldo Junqueira. GCB, Ribas, Guilherme Carvalhal; Bento, Ricardo Ferreira; Rodrigues AJ. Anaglyphic three-dimensional stereoscopic printing: revival of an old method for anatomical and surgical teaching. J neurosurg [Internet]. 2001;95(6):1057-66.

2. Parraga RG, Ribas GC, Andrade SE, de Oliveira E. Microsurgical anatomy of the posterior cerebral artery in three-dimensional images. World Neurosurg [Internet]. 2011/04/16. 2011;75(2):233-57. Available from:

http://www.ncbi.nlm.nih.gov/entrez/query.fcgi?cmd=Retrieve\&db=PubMed\&dopt=Citation\&list_uids=2149 2726

3. Quintana LM. Anaglyph 3D in Vascular Neurosurgery: Excellent Exercise for the Neurosurgeon's Brain. World Neurosurg [Internet]. 2014 Sep;82(3-4):e417-8. Available from:

https://linkinghub.elsevier.com/retrieve/pii/S1878875013004476

4. Shimizu S, Tanaka R, Rhoton Jr. AL, Fukushima Y, Osawa S, Kawashima M, et al. Anatomic dissection and classic three-dimensional documentation: a unit of education for neurosurgical anatomy revisited. Neurosurgery [Internet]. 2006/04/28. 2006;58(5):E1000; discussion E1000. Available from: http://www.ncbi.nlm.nih.gov/entrez/query.fcgi?cmd=Retrieve\&db=PubMed\&dopt=Citation\&list_uids=1663 9290

5. Fernández-Miranda JC, Rhoton AL, Álvarez-Linera J, Kakizawa Y, Choi C, De Oliveira EP, et al. Threedimensional microsurgical and tractographic anatomy of the white matter of the human brain. Neurosurgery [Internet]. 2008;62(6 Suppl 3):SHC989-1026; discussion SHC1026-8. Available from: http://www.ncbi.nlm.nih.gov/entrez/query.fcgi?cmd=Retrieve\&db=PubMed\&dopt=Citation\&list_uids=1869 5585

6. Ribas GC, Ribas EC, Rodrigues Jr AJ. O cérebro, a visão tridimensional, e as possibilidades de reprodução de imagens estereoscópicas. Rev Med (São Paulo). 2006;85(3):78-90.

7. Getty DJ, Green PJ. Clinical applications for stereoscopic 3-D displays. J Soc Inf Disp [Internet]. 2007;15(6):377-84. Available from: http://doi.wiley.com/10.1889/1.1828693

8. Gonzalo-Domínguez M, Hernández-Rodríguez C, Ruisoto P, Juanes JA, Balbin JMM, Prats-Galino A. 3D 
reconstructions of brain ventricles using anaglyph images. In: Proceedings of the Fourth International Conference on Technological Ecosystems for Enhancing Multiculturality - TEEM '16 [Internet]. New York, New York, USA: ACM Press; 2016. p. 491-4. Available from:

http://dl.acm.org/citation.cfm?doid=3012430.3012562

9. Abarca-Olivas J, Monjas-Cánovas I, López-Álvarez B, Lloret-García J, Sanchez-del Campo J, GrasAlbert JR, et al. Estudio endoscópico endonasal 3D de la anatomía de la base de cráneo. Neurocirugia [Internet]. 2014 Jan;25(1):1-7. Available from:

https://linkinghub.elsevier.com/retrieve/pii/S1130147313000882

10. Henn JS, Lemole GM, Ferreira MAT, Gonzalez LF, Schornak M, Preul MC, et al. Interactive stereoscopic virtual reality: a new tool for neurosurgical education. J Neurosurg. 2002;96(1):144-9.

11. Rubino PA, Bottan JS, Houssay A, Salas López E, Bustamante J, Chiarullo M, et al. Three-Dimensional Imaging as a Teaching Method in Anterior Circulation Aneurysm Surgery. World Neurosurg [Internet]. 2014 Sep;82(3-4):e467-74. Available from: https://linkinghub.elsevier.com/retrieve/pii/S1878875013003513

12. Rollmann W. Zwei neue stereoskopische Methoden. Ann Phys. 1853;166(9):186-7.

13. D’Almeida J-C. Nouveil Appareil Stéréoscopique. Bull la Soc Française Photogr. 1858;4:260-2.

14. Spiriev T, Nakov V, Laleva L, Tzekov C. OsiriX software as a preoperative planning tool in cranial neurosurgery: A step-by-step guide for neurosurgical residents. Surg Neurol Int [Internet]. 2017;8(1):241. Available from: http://www.surgicalneurologyint.com/text.asp?2017/8/1/241/216286

15. Chaddad-Neto F, Campos Filho JM, Doria-Netto HL, Faria MH, Ribas GC, Oliveira E. The pterional craniotomy: tips and tricks. Arq Neuropsiquiatr [Internet]. 2012/09/20. 2012;70(9):727-32. Available from: https://www.ncbi.nlm.nih.gov/pubmed/22990732

16. Woods AJ, Harris CR, Leggo DB, Rourke TM. Characterizing and reducing crosstalk in printed anaglyph stereoscopic 3D images. Opt Eng. 2013;

17. Sarnat HB, Netsky MG. Evolution of the nervous system. 2nd ed. New York: Oxford University Press; 1981.

18. Ferwerda JG. The world of 3-D. 2nd ed. Borger, The Netherlands: 3D Book Productions; 1990. 
19. Hubel D, Wiesel T. Brain mechanisms of vision. In: The Brain, a Sceintific American book. San Francisco: W. H. Freeman and Company; 1979. p. 84-97.

20. Wolfgram DE. Adventuras em 3D. São Paulo: Berkeley Brasil Editora; 1993.

21. Brewster D. The Stereoscope: its History, Theory and Constrcution, with is Application to the fine and useful Arts and to Education. London: Fifty Wood Engravings; 1856.

22. Nam KW, Park J, Kim IY, Kim KG. Application of Stereo-Imaging Technology to Medical Field. Healthc Inform Res [Internet]. 2012;18(3):158-63. Available from:

https://synapse.koreamed.org/DOlx.php?id=10.4258/hir.2012.18.3.158

23. Davidson JM. Remarks on the value of stereoscopic photography and skiagraphy: Records of clinical and pathological appearances. Br Med J. 1898;2(1979):1669-72.

24. Gatesy SM, Shubin NH, Jenkins Jr. FA. Anaglyph stereo imaging of dinosaur track morphology and microtopography. Palaeontol Electron. 2005;8(1):814.

25. Zollhavarieh SM, Vatanchian M. Development of an Anaglyph Anatomical Atlas of Rabbit as a New Generation of Printable 3D Anatomical Atlases. ASJ. 2014;11(1):59-65.

26. Garcia-Ruiz MÁ, Santana PC, Molina I. Towards effective use of stereoscopic visualization of molecular models in educational settings. In: Proceedings of Canada International Conference on Education (CICE2013). Toronto; 2013.

27. Murillo-García FG, Alcántara-Ayala I, Ardizzone F, Cardinali M, Fiourucci F, Guzzetti F. Satellite stereoscopic pair images of very high resolution: a step forward for the development of landslide inventories. Landslides. 2015;

28. Abla AA, Lawton MT. Three-Dimensional Hollow Intracranial Aneurysm Models and Their Potential Role for Teaching, Simulation, and Training. World Neurosurg [Internet]. 2015 Jan;83(1):35-6. Available from: https://linkinghub.elsevier.com/retrieve/pii/S1878875014000795

29. Benet A, Plata-Bello J, Abla AA, Acevedo-Bolton G, Saloner D, Lawton MT. Implantation of 3D-Printed Patient-Specific Aneurysm Models into Cadaveric Specimens: A New Training Paradigm to Allow for Improvements in Cerebrovascular Surgery and Research. Biomed Res Int [Internet]. 2015;2015:1-9. Available from: http://www.hindawi.com/journals/bmri/2015/939387/ 
30. Wurm G, Lehner M, Tomancok B, Kleiser R, Nussbaumer K. Cerebrovascular Biomodeling for Aneurysm Surgery. Surg Innov [Internet]. 2011 Sep;18(3):294-306. Available from:

http://journals.sagepub.com/doi/10.1177/1553350610395031

31. Erbano BO, Opolski AC, Olandoski M, Foggiatto JA, Kubrusly LF, Dietz UA, et al. Rapid prototyping of three-dimensional biomodels as an adjuvant in the surgical planning for intracranial aneurysms. Acta Cir Bras [Internet]. 2013 Nov;28(11):756-61. Available from:

http://www.scielo.br/scielo.php?script=sci_arttext\&pid=S0102-86502013001100002\&lng=en\&tlng=en

32. Kimura T, Morita A, Nishimura K, Aiyama H, Itoh H, Fukaya S, et al. Simulation of and training for cerebral aneurysm clipping with 3-dimensional models. Neurosurgery [Internet]. 2009 Oct;65(4):719-26. Available from: https://academic.oup.com/neurosurgery/article/65/4/719/2555747

33. Liu Y, Gao Q, Du S, Chen Z, Fu J, Chen B, et al. Fabrication of cerebral aneurysm simulator with a desktop 3D printer. Sci Rep [Internet]. 2017 May;7:44301. Available from: http://www.nature.com/articles/srep44301

34. Mashiko T, Otani K, Kawano R, Konno T, Kaneko N, Ito Y, et al. Development of Three-Dimensional Hollow Elastic Model for Cerebral Aneurysm Clipping Simulation Enabling Rapid and Low Cost Prototyping. World Neurosurg [Internet]. 2015 Mar;83(3):351-61. Available from: https://linkinghub.elsevier.com/retrieve/pii/S1878875013013570

35. Müns A, Meixensberger J, Lindner D. Evaluation of a novel phantom-based neurosurgical training system. Surg Neurol Int. 2014;5:173.

36. Randazzo M, Pisapia JM, Singh N, Thawani JP. 3D printing in neurosurgery: A systematic review. Surg Neurol Int. 2016;7(33):S801-9.

37. Ryan JR, Almefty KK, Nakaji P, Frakes DH. Cerebral Aneurysm Clipping Surgery Simulation Using Patient-Specific 3D Printing and Silicone Casting. World Neurosurg [Internet]. 2016 Apr;88:175-81. Available from: https://linkinghub.elsevier.com/retrieve/pii/S1878875016001121

38. Wang L, Ye X, Hao Q, Ma L, Chen X, Wang H, et al. Three-dimensional intracranial middle cerebral artery aneurysm models for aneurysm surgery and training. J Clin Neurosci [Internet]. 2018 Apr;50:7782. Available from: https://linkinghub.elsevier.com/retrieve/pii/S0967586817314492 
39. Balogh A, Preul MC, Schornak M, Hickman M, Spetzler RF. Intraoperative stereoscopic QuickTime Virtual Reality. J Neurosurg. 2004;100(4):591-6.

40. O'Sullivan E, Mitchell BS. An improved composition for embalming fluid to preserve cadavers for anatomy teaching in the United Kingdom. J Anat. 1993;182 ( Pt 2:295-7.

41. Aversi-ferreira TA, Monteiro CA, Maia FA, Paula A, Guimarães R, Cruz MR. Tridimensionais Construídos Durante O Aprendizado Neurophysiology Study Associated With Three-Dimensional. Biosci J. 2008;24(1):98-103.

42. Augusto M, Ferreira T, Nataniel S, Gusmão S, Spetzler RF. Realidade virtual e estereoscopia no ensino da neuroanatomia e neurocirurgia. Arq Bras Neurocir. 2013;32(4):211-20.

43. Smith DM, Oliker A, Carter CR, Kirov M, McCarthy JG, Cutting CB. A virtual reality atlas of craniofacial anatomy. Plast Reconstr Surg. 2007;120(6):1641-6.

44. Yeung YY. A learner-centered approach for training science teachers through virtual reality and 3D visualization technologies: Practical experience for sharing. In: The Fourth International Forum on Education Reform. 2004. p. 1-8.

45. Raymond J, Salazkin I, Gevry G, Nguyen TN. Interventional neuroradiology: the role of experimental models in scientific progress. AJNR Am J Neuroradiol [Internet]. 2007 Mar;28(3):401-5. Available from: http://www.ncbi.nlm.nih.gov/pubmed/17353303

46. Yatomi K, Yamamoto M, Mitome-Mishima Y, Nonaka S, Yoshida K, Oishi H, et al. New Experimental Model of Terminal Aneurysms in Swine: Technical Note. J Neurol Surg Part A Cent Eur Neurosurg [Internet]. 2012 Jul;73(06):397-400. Available from: http://www.thieme-connect.de/DOI/DOI?10.1055/s$0032-1322592$

47. Magaldi MO, Nicolato A, Godinho J V, Santos M, Prosdocimi A, Malheiros JA, et al. Human Placenta Aneurysm Model for Training Neurosurgeons in Vascular Microsurgery. Neurosurgery [Internet]. 2014 Dec;10:592-601. Available from: https://academic.oup.com/ons/articlelookup/doi/10.1227/NEU.0000000000000553

48. Mandel M, Amorim R, Paiva W, Prudente M, Teixeira M, Andrade A. 3D Preoperative Planning in the ER with OsiriX®: When There is No Time for Neuronavigation. Sensors [Internet]. 2013 May;13(5):6477-91. 
Available from: http://www.mdpi.com/1424-8220/13/5/6477

49. Woods AJ, Harris CR. Comparing levels of crosstalk with red/cyan, blue/yellow, and green/magenta anaglyph 3D glasses. In: Woods AJ, Holliman NS, Dodgson NA, editors. 2010. p. 75240Q-75240Q. Available from: http://proceedings.spiedigitallibrary.org/proceeding.aspx?doi=10.1117/12.840835 


\section{FIGURE LEGENDS}

Figure 1. Primary steps for development of stereoscopic anaglyph images from volume rendering reconstructions with CT scan - screen captures of the open-source Horos Software. A. Volume rendering. $\boldsymbol{B}$. Croping. $\boldsymbol{C}$ to $\boldsymbol{D}$. Decomposition of head positioning: neutral position (C), extension and rotation (D). $\boldsymbol{E}$. Rotation of the final virtual object.

Figure 2. Geometric representation of the rational of stereoscopic acquisition by virtual object rotation. The rotation angle can be calculated using simple trigonometric ratios in right triangles, and expressed as a function of the object distance and the parallax obtained by horizontal displacement of a camera. With a virtual object, this angle can be applied for $y$-axis rotation and simulation of a concrete situation. $\boldsymbol{A}$. Rotation needed for a displacement corresponding to $1 / 30$ of the distance of the object. B. General rule for a displacement of $n$ um corresponding to of $1 / n$ of the distance to the object.

Figure 3. Stereoscopic overview of the arterial circle of the brain and skull base. A. Superior view. Two small aneurysms are visualized: one at the bifurcation of the middle cerebral artery, the other at the anterior communicating artery complex. The right pre-communicating segment of the anterior cerebral artery is absent in this patient. B. Antero-superior view. C. Lateral view. A supra-clinoid retrocarotidian anerusym is visualized in the Posterior Communicating segment of the internal carotid artery. The right communicating artery is absent in this patient. Note that different color tones are possible, including tones of grey, with a good stereoscopic result, albeit a loss of contrast between arterial and bony structures (decreases from $A$ to $C$ ).

Figure 4. Stereoscopic anaglyph three-dimensional reconstruction of surgical perspectives of normal and pathological intracranial arteries. A. Internal carotid artery and branches, perspective as from a subfrontal approach. B. Anterior communicating argery aneurysm, a right pterional approach. A second contralateral retrocarotidian aneurysm is visualized through the same craniotomy. C. Basilar Artery aneurysm (subtemporal approach). 